\title{
Avaliação do potencial genotóxico do extrato bruto de Pyrostegia venusta (Ker Gawl.) Miers, Bignoneaceae, em medula óssea de camundongos
}

\author{
Eduardo A. Magalhães, ${ }^{1}$ Gabriel J. Silva Júnior, ${ }^{1}$ Thiago Augusto de Campos, ${ }^{2}$ \\ Luciana P. Silva, ${ }^{2}$ Regildo M. G. Silva ${ }^{* 2}$ \\ ${ }^{1}$ Laboratório de Farmacognosia, Faculdade de Ciências da Saúde, Centro Universitário de Patos de Minas, \\ Universidade do Estado de Minas Gerais, Rua Major Gote, 808, 38702-054 Bairro Alto Caiçara, \\ Patos de Minas-MG, Brasil \\ ${ }^{2}$ Departamento de Ciências Biológicas, Faculdade de Ciências e Letras, Universidade Estadual Paulista, \\ Av. Dom Antônio, 2100, 19806-900 Bairro Parque Universitário, Assis-SP, Brasil.
}

\begin{abstract}
RESUMO: Pyrostegia venusta (Ker Gawl.) Miers, Bignoneaceae, é utilizada no tratamento de vitiligo e de outras doenças, mas seus efeitos genotóxicos não são conhecidos. Neste sentido, o presente estudo teve por objetivo avaliar o efeito genotóxico de extratos de $P$. venusta em camundongos utilizando os Testes de Micronúcleo (MN) e o de Aberração Cromossômica (AC). $\mathrm{O}$ vegetal foi coletado, selecionado, seco, triturado e extraído com etanol. Camundongos de 40 $\mathrm{g}$ foram divididos em grupos experimentais e controles. Os grupos experimentais receberam concentrações crescentes do extrato $(50,100$ e $200 \mathrm{mg} / \mathrm{kg}$ por peso corporal), por v.o. O grupo controle negativo $(\mathrm{CN})$ recebeu água. $\mathrm{O}$ grupo controle positivo $(\mathrm{CP})$ recebeu Ciclofosfamida ${ }^{\mathbb{B}}$ por v.i. Realizou-se o sacrifício, retirada da medula óssea, homogeneização e preparação das lâminas. As freqüências de eritrócitos policromáticos micronucleados ( $\mathrm{EPCMN}$ ) foram: $\mathrm{CN}=0,35 \pm 0,09$; $\mathrm{CP}=2,87 \pm 1,78 ; 50=0,09 \pm 0,04 ; 100=0,16 \pm 0,08$ e $200=0,10 \pm 0,03$. O teste de AC apresentou as seguintes freqüências: $\mathrm{CN}=0,12 \pm 1,87 ; \mathrm{CP}=0,62 \pm 5,61 ; 50=0,12 \pm 1,58 ; 100=0,072 \pm 0,54 \mathrm{e}$ $200=0,124 \pm 1,64$. As freqüências de EPCMN dos grupos experimentais foram significantemente inferiores quando comparadas com as dos controles. A freqüência de cromossomos aberrantes não teve diferença significativa se comparada com o $\mathrm{CN}$, mas foi estatisticamente menor que a do CP. P.venusta não apresentou atividade genotóxica.
\end{abstract}

Unitermos: teste de micronúcleo, aberrações cromossômicas, genotoxicidade, Pyrostegia venusta, camundongos.

\begin{abstract}
The Evaluation of the genotoxic potency of the Pyrostegia venusta (Ker Gawl.) Miers, Bignoneaceae, crude extract on bone marrow of mice". Pyrostegia venusta (Ker Gawl.) Miers, Bignoneaceae, is used in the treatment of vitiligo and other diseases, but its genotoxic effects are unknown. In this way, this study aimed to evaluate the genotoxic effect of extracts of $P$. venusta in mice using the micronucleus $(\mathrm{MN})$ and chromosome aberration tests $(\mathrm{CA})$. The plant was collected, selected, dried, pounded and extracted with ethanol. Mice weighing $40 \mathrm{~g}$ were divided in experimental and control groups. The experimental groups received different concentrations (50, 100 , and $200 \mathrm{mg} / \mathrm{kg}$ body weight), by oral gavage. The negative control group (NC) received water. The positive control group (PC) received Ciclophosphamide ${ }^{\circledR}$ by $v . i$. It was performed the sacrifice, removal of bone marrow, homogenization and slides preparation. Frequency of micronucleated polychromatic erythrocytes (MNPCE) was: $\mathrm{NC}=0.35 \pm 1.87 ; \mathrm{PC}=2.87 \pm 9.02 ; 50=0.09 \pm 0.83$; $100=0.16 \pm 0.10$ e $200=0.10 \pm 0.71$. The $\mathrm{CA}$ test showed the frequency: $\mathrm{NC}=0.12 \pm 1.87 ; \mathrm{PC}=$ $0.62 \pm 5.61 ; 50=0.12 \pm 1.58 ; 100=0.072 \pm 0.54$ e $200=0.124 \pm 1.64$. The frequency of MNPCE of experimental controls was significantly lower when compared with $\mathrm{NC}$, but it was statistically lower than PC's frequency. P.venusta didn't show genotoxicity activity.
\end{abstract}

Keywords: micronucleus test, chromosomal aberrations, genotoxicity, Pyrostegia venusta, mice. 


\section{INTRODUÇ̃̃OO}

Pyrostegia venusta (Ker Gawl.) Miers, Bignoneaceae, também conhecida como Pyrostegia ígnea, é uma liana trepadeira que cresce junto a outras plantas e a escoras, suas flores são tubulares de coloração alaranjada e são dispostas em cachos com quinze a vinte flores em média (Gilman, 1999). Esta planta apresenta expressiva dispersão em quase todo o sul e sudeste do Brasil (De Sampaio, 1991) sendo chamada na medicina folclórica de "cipó ou flor de São João". O extrato alcoólico de flores e folhas é utilizado na medicina popular como um remédio para tratar manchas brancas no corpo (leucoderma, vitiligo) (Ferreira et al., 2000). Uma infusão preparada a partir de cascas e raízes de $P$. venusta é amplamente usada no tratamento de infecções uterinas e do trato genital feminino, erisipela e icterícia (hiperbilirubinemia e deposição de pigmentos biliares) em bebês recém nascidos (Sens, 2002).

Estudos fitoquímicos têm demonstrado a presença de aminoácidos e açúcares no néctar de diferentes espécies do gênero Pyrostegia, incluindo flores de P. venusta (Galetto et al., 1994). $\beta$-sitosterol, $n$-hentriacontano $\left(n-\mathrm{C}_{31} \mathrm{H}_{64}\right)$, 7-O- $\beta$-D-glicopiranosilacacetina e meso-inositol (myoinositol) foram isolados de suas flores (Dubey \& Misra, 1976). Enquanto o extrato etanólico das raízes forneceu quatro substâncias: alantoína, esteroides $\beta$-sitosterol e $3 \beta$ $O-\beta$-D-glicopiranosilsitosterol e a flavanona hesperidina (Ferreira et al., 2000). Na extração concentrada de folhas, foi possível determinar a presença de classes diferentes de flavonoides e fenóis, independente do local de ocorrência da planta (cerrado ou floresta) (Santos \& Blatt, 1998). A avaliação de quarenta espécies de Bignoniaceae, incluindo $P$. venusta, revelou a presença de componentes fenólicos livres e grupos siringila (Satyavathi et al., 1984). O padrão de antocianinas florais apresentou pouca variação dentro da família Bignoniaceae (Scogin, 1980).

O provável potencial terapêutico do extrato bruto de $P$. venusta associado à ausência de qualquer registro sobre sua mutagenicidade em células de mamíferos conduziram ao presente estudo que visa avaliar possíveis efeitos clastogênicos desse extrato através dos Testes de Micronúcleo (MN) e o de Aberração Cromossômica (AC) em medula óssea de roedores, sendo que, tais testes são aceitos e recomendados para a avaliação e o registro de produtos naturais e farmacêuticos.

\section{MATERIAL E MÉTODOS}

\section{Obtenção do material vegetal e extrato}

O material vegetal foi coletado em área de cerrado do município de Patos de Minas-MG (18³1'40.34"S e $\left.46^{\circ} 32^{\prime} 19.75^{\prime \prime} \mathrm{W}\right)$. A planta foi identificada pela Bióloga MSc. Alice de Fátima Amaral e um espécime comprovativo (exsicata) foi depositado no Herbário Mandevilla no Centro Universitário de Patos de Minas (UNIPAM)-Universidade
Estadual de Minas Gerais (UEMG) sob o número de registro MGHM0430. O extrato bruto (EB) foi obtido a partir das flores da $P$. venusta, utilizando como extrator o solvente etanol, na proporção 1:10 (p:v) e misturado mecanicamente a temperatura ambiente por $24 \mathrm{~h}$ (extração conduzida em triplicata) seguido de evaporação do solvente até a obtenção de um extrato seco, padronizado de acordo com a técnica descrita por Santos \& Blatt (1998), adaptada para extração de flores secas e trituradas.

\section{Animais e tratamentos}

Foram utilizados camundongos Swiss albinos, machos, de 9-12 semanas de vida e peso de 35-40 g, obtidos no centro de criação de animais (Biotério Central, UNIPAM). Os animais foram mantidos em caixas de polietileno, em ambiente controlado $\left(25 \pm 4{ }^{\circ} \mathrm{C}, 55 \pm 5 \%\right.$ de umidade), controle de claro/escuro a cada $12 \mathrm{~h}$ (das 7:00 às 19:00). Comida e água disponível ad libitum. Foram alojados cinco animais por caixa e aleatoriamente divididos em cinco grupos: 1) Animais que receberam água destilada (controle negativo, $\mathrm{CN}$ ) por gavagem; 2) Animais que receberam 2,0 mg/kg de peso corporal (p.c.) de Ciclofosfamida ${ }^{\circledR}$ (CF) em água de injeção (controle positivo, CP) por uma única injeção intraperitoneal (ip); 3 , 4 e 5) Animais que foram tratados com 50, 100 e $200 \mathrm{mg} /$ kg p.c. respectivamente de EB de Pyrostegia venusta (Ker Gawl.) Miers, Bignoneaceae, diariamente, durante 7 d, por gavagem. Os animais foram sacrificados por deslocação cervical 24 h após o período experimental de uma semana. Este estudo foi aprovado pelo Comitê de Ética Animal da UNIPAM, UEMG, Patos de Minas-MG, Brasil (Protocolo 88/07).

\section{Critério de escolha e Teste do Micronúcleo em células de medula óssea de camundongos}

Efeitos genotóxicos foram avaliados em células da medula óssea de camundongos pelo Teste de Micronúcleo de acordo com Schmid (1975). Imediatamente após o sacrifício do animal, um fêmur foi removido e a medula óssea foi retirada e emulsionada até obter uma suspensão, a qual foi transferida para tubos de centrifugação contendo 2 $\mathrm{mL}$ de soro fetal bovino(SFB). A suspensão de medula óssea foi centrifugada a $1000 \mathrm{rpm}$ por $10 \mathrm{~min}$ e o sobrenadante foi descartado. O sedimento foi ressuspendido em uma gota de SFB. Uma pequena porção desta suspensão foi colocada em lâminas de microscópio onde se realizou o esfregaço. Após $24 \mathrm{~h}$ secando a temperatura ambiente, as lâminas foram fixadas com metanol absoluto por $5 \mathrm{~min}$ e armazenadas a temperatura ambiente ou diretamente coradas para análise. Para coloração utilizou-se uma solução de Giemsa (Sigma Chemical Co., St. Louis, MO, USA) preparada com tampão fosfato de sódio (0,06 M; pH 6,8) e tampão fosfato de potássio $(0,06 \mathrm{M}$; pH 6,8$)$ na proporção de 1:1. As lâminas foram coradas por $5 \mathrm{~min}$, 
lavadas com água destilada para remoção do excesso de corante e secas a temperatura ambiente.

As lâminas foram examinadas sob aumento de 1000 x em microscópio óptico (Olympus, Japão). O critério para contagem de micronúcleos foi baseado essencialmente no diâmetro, na forma do micronúcleo e na sua coloração, de acordo com Krishna \& Hayashi (2000). Para avaliar a indução na formação de $\mathrm{MN}$ foi determinado o número de eritrócitos policromáticos micronucleados (EPCMN) em 2000 EPC por amostra de camundongos.

\section{Teste de aberração cromossômica}

As células da medula óssea foram coletadas do fêmur por injeção de uma solução de 2,2\% de citrato de sódio e centrifugadas a $1000 \mathrm{rpm}$ por $10 \mathrm{~min}$. Após centrifugação, as células da medula óssea foram tratadas com $5 \mathrm{~mL}$ de solução hipotônica de $0,075 \mathrm{M} \mathrm{KCl}$ préaquecida por $20 \mathrm{~min}$ a $37^{\circ} \mathrm{C}$, e ressuspendidas duas vezes em $5 \mathrm{~mL}$ de fixador Carnoy frio (metanol-ácido acético glacial, 3:1, v/v) por 20 min a temperatura ambiente. Após a centrifugação final, as células foram cuidadosamente misturadas usando a ponta de uma pipeta Pasteur e foram gotejadas a uma altura de 3-4 cm em lâminas molhadas e limpas. As mesmas foram coradas em Giemsa 10\% por 20 min. A contagem e classificação de aberrações foram feitas como descritas por Preston et al. (1987). Aberrações cromossômicas foram contadas em cinquenta metáfases para cada camundongo sob aumento de 1000 x com microscópio óptico (Olympus, Japão). Analisou-se o perfil total de aberrações cromossômicas através da observação de quebras, formação de anéis e de gaps cromossômicos. Apenas metáfases bem espalhadas com $42 \pm 1$ cromossomos foram aleatoriamente analisadas. Os danos cromossômicos foram avaliados comparando os grupos tratados com os grupos controle positivo e negativo.

\section{Análise estatística}

Os resultados foram expressos comomédia \pm desvio padrão (DP) para comparar freqüências de EPCMN e EPC entre grupos tratados e controles. Os dados foram analisados estatisticamente pelo teste-U não-paramétrico MannWhitney, com nível de significância $\alpha=0,05$, utilizando o sotfware SPSS 12.0 para PCs (SPSS, Chicago, IL) para análises estatísticas do ensaio de micronúcleos.

Os resultados das análises de aberrações cromossômicas foram expressos como média \pm DP. As diferenças nas porcentagens de média entre grupos tratados e controles foram avaliadas usando o teste do Quiquadrado $\left(\chi^{2}\right)(\mathrm{P} \leq 0,05)$.

\section{RESULTADOS}

\section{Teste de micronúcleo}

As freqüências de eritrócitos policromáticos micronucleados $(\% \mathrm{EPCMN} \pm \mathrm{DP})$ para os camundongos do grupo $\mathrm{CN}$ e aqueles dos grupos tratados com diferentes concentrações $(50,100$ e $200 \mathrm{mg} / \mathrm{kg}$ p.c.) de EB de Pyrostegia venusta (Ker Gawl.) Miers, Bignoneaceae, foram, respectivamente, $0,35 \pm 0,09,0,09 \pm 0,04,0,16 \pm 0,08$ e $0,10 \pm 0,03$. As frequências de $E P C M N$ para ratos tratados com todas as diferentes concentrações de EB foram significantemente diferentes do $\mathrm{CN}$ (Teste- $\mathrm{U}, \mathrm{P} \leq$ 0.05). A freqüência de EPCMN, para animais do grupo $\mathrm{CP}$ $(2,87 \pm 1,78)$ diferiu significantemente (teste- $\mathrm{U}, \mathrm{P} \leq 0,05)$ do controle negativo e das frequências dos grupos tratados com EB de P. venusta (Tabela 1).

Tabela 1. Resultados do Teste de Micronúcleo mostrando a frequência de eritrócitos policromáticos micronucleados (EPCMN) em camundongos Swiss albinos tratados com extrato bruto (EB) de Pyrostegia venusta e Ciclofosfamida ${ }^{\circledR}(\mathrm{CF})$. Cinco grupos $(\mathrm{n}=5$, animais: A1 a A5) e análise de dois mil eritrócitos policromáticos (EPC) por camundongo.

\begin{tabular}{|c|c|c|c|c|c|c|c|c|c|}
\hline \multicolumn{2}{|c|}{$\begin{array}{l}\text { Tratamento } \\
(\mathrm{mg} / \mathrm{kg} \text { p.c.) }\end{array}$} & \multicolumn{6}{|c|}{ EPCMN/Animal } & \multirow[t]{2}{*}{$\mathrm{N}^{\mathrm{o}}$ total de EPCMN } & \multirow[t]{2}{*}{$0 / 0 \mathrm{EPCMN} \pm \mathrm{DP}$} \\
\hline EB & & $\mathrm{CF}$ & $\mathrm{A}_{1}$ & $\mathrm{~A}_{2}$ & $\mathrm{~A}_{3}$ & $\mathrm{~A}_{4}$ & $\mathrm{~A}_{5}$ & & \\
\hline 0,0 & + & 0,0 & 07 & 10 & 06 & 07 & 05 & 35 & $0,35 \pm 0,09$ \\
\hline 50,0 & + & 0,0 & 02 & 01 & 03 & 01 & 02 & 09 & $0,09 \pm 0,04^{*}$ \\
\hline 100,0 & + & 0,0 & 02 & 02 & 03 & 03 & 06 & 16 & $0,16 \pm 0,08^{*}$ \\
\hline 200,0 & + & 0,0 & 02 & 01 & 03 & 02 & 02 & 10 & $0,10 \pm 0,03^{*}$ \\
\hline 0,0 & + & 2,0 & 55 & 53 & 73 & 56 & 50 & 286 & $2,87 \pm 1,78$ \\
\hline
\end{tabular}

* Significantemente diferente dos controles positivo e negativo $(\mathrm{P} \leq 0,05)$.

\section{Análise de aberrações cromossômicas}

Os resultados do teste de aberração cromossômica mostraram a formação de quebras, gaps e anéis cromossômicos. Os tratamentos com EB de $P$. venusta nas concentrações de $50(12,0 \pm 3,16)$ e $200(11,6 \pm 3,84) \mathrm{mg} /$ $\mathrm{kg}$ p.c. não apresentaram diferenças significativas quando comparados com o $\mathrm{CN}(12,0 \pm 3,74)$. Entretanto, o grupo tratado com $100(7,20 \pm 1,09) \mathrm{mg} / \mathrm{kg}$ p.c. de EB de $P$. venusta apresentou um decréscimo significativo no total de aberrações cromossômicas, principalmente quebras e gaps cromossômicas, comparado ao $\mathrm{CN}\left(\chi^{2}: \mathrm{P} \leq 0,05\right)$. As freqüências de aberrações cromossômicas, considerando quebras, gaps e anéis cromossômicos, para os animais 
tratados com diferentes concentrações do EB foram significantemente diferentes do CP $(62,0 \pm 11,22)\left(\chi^{2}: \mathrm{P} \leq 0,05\right)$ (Tabela 2).

Tabela 2. Distribuição dos diferentes tipos de aberrações cromossômicas, em células da medula óssea de camundongos Swiss com extrato bruto de $P$. venusta e controles positivo e negativo (cinco grupos para cada tratamento e controles).

\begin{tabular}{|c|c|c|c|c|c|c|c|c|c|}
\hline \multicolumn{3}{|c|}{$\begin{array}{l}\text { Tratamento } \\
(\mathrm{mg} / \mathrm{kg} \text { p.c.) }\end{array}$} & \multirow[t]{2}{*}{$\begin{array}{l}\text { Total de } \\
\text { Metáfases }\end{array}$} & \multicolumn{3}{|c|}{ Aberrações estruturais } & \multirow{2}{*}{$\begin{array}{c}\text { Total de } \\
\text { aberrações } \\
\text { cromossômicas }\end{array}$} & \multirow{2}{*}{\multicolumn{2}{|c|}{$\begin{array}{l}\text { Células com aberrações } \\
\text { cromossômicas } 0 / 0 \pm \mathrm{DP}\end{array}$}} \\
\hline EB & & $\mathrm{CF}$ & & $\begin{array}{c}\text { Quebras } \\
\text { cromossômicas }\end{array}$ & Gaps & Anéis & & & \\
\hline 0,0 & + & 0,0 & 250 & 24 & 6 & 0 & 30 & 12,0 & $\pm 3,74 \mathrm{a}^{*}$ \\
\hline 50,0 & + & 0,0 & 250 & 19 & 9 & 2 & 30 & 12,0 & $\pm 3,16^{\mathrm{a}}$ \\
\hline 100,0 & + & 0,0 & 250 & 15 & 1 & 2 & 18 & 7,2 & $\pm 1,09^{\mathrm{b}}$ \\
\hline 200,0 & + & 0,0 & 250 & 24 & 5 & 0 & 29 & 11,6 & $\pm 3,84^{\mathrm{a}}$ \\
\hline 0,0 & + & 2,0 & 250 & 121 & 26 & 8 & 155 & 62,0 & $\pm 11,22^{\mathrm{c}}$ \\
\hline
\end{tabular}

*Letras semelhantes para valores que não apresentam diferenças significativas $(\mathrm{P}<0,05)$.

\section{DISCUSSÃO}

A avaliação da indução de micronúcleos é o principal teste in vivo em uma bateria de testes genotóxicos e é recomendado por agências fiscalizadoras em todo mundo como parte da avaliação de segurança dos produtos químicos e naturais. $\mathrm{O}$ ensaio, quando realizado corretamente, detecta ambos os efeitos: clastogênicos e aneugênicos (Krishna \& Hayashi, 2000).

Micronúcleos em eritrócitos jovens surgem principalmente a partir de fragmentos acêntricos ou cromossomos que são incapazes de migrar seguindo o fuso mitótico durante a divisão celular do tecido hematopoiético (Salamone \& Heddle, 1983; Ouanes et al., 2003). Um aumento na frequência de EPCMN em testes com animais tratados com diferentes substâncias é uma indicação de dano cromossômico induzido (Krishna \& Hayashi, 2000).

O ensaio de aberração cromossômica é amplamente utilizado para a avaliação de dano ao DNA, que é geralmente mensurado como quebras simples, quebras duplas ou aberrações cromossômicas, e o aumento na suas frequências é normalmente associado com mutagênese e carcinogênese (Surh \& Ferguson, 2003).

No presente estudo, a frequência de EPCMN de grupos tratados com EB de Pyrostegia venusta (Ker Gawl.) Miers, Bignoneaceae, foi significantemente menor que as frequências observadas no $\mathrm{CP}$, resultando, eventualmente, em até uma menor frequência de EPCMN quando comparadas com as obtidas no CN. A Ciclofosfamida ${ }^{\mathbb{R}}$ tem sido amplamente usada como um controle positivo em ensaios de micronúcleos em roedores (Krishna \& Hayashi, 2000) devido à capacidade de indução de EPCMN. Todavia, a diminuição das frequências de EPCMN comparadas com os respectivos controles sugere que o $\mathrm{EB}$ não age como uma genotoxina, podendo inclusive possuir componentes que exercem um efeito antigenotóxico.

A freqüência de EPCMN encontrada nos grupos tratados com EB de $P$. venusta está em conformidade com os estudos de Raj \& Katz (1984) que observaram o efeito antimutagênico de $\beta$-sitosterol em células da medula óssea de camundongos, componente descoberto em análises fitoquímicas de extratos de P. venusta (Dubey \& Misra, 1976).

O decréscimo das frequências de EPCMN nos grupos tratados com EB de $P$. venusta $(50,100$ e 200 $\mathrm{mg} / \mathrm{kg}$ p.c.) foram, respectivamente $74,3,54,3$ e $71,4 \%$ quando comparados com a frequência observada no $\mathrm{CN}$. Este decréscimo pode ser associado com a presença de hesperidina no EB de P. venusta (Ferreira et al., 2000). Al-Majed et al. (2006) descreveram os efeitos citológicos e bioquímicos deste componente, presente também em extratos de valeriana, em células somáticas e germinativas de camundongos Swiss albino.

Outros componentes como fenóis, grupos siringila e polifenóis livres, encontrados na família Bignoniaceae podem estar associados à diminuição da frequência de EPCMN em grupos tratados (Satyavathi et al., 1984). Soobrattee et al. (2005) observaram que estes componentes têm propriedades antioxidantes atribuíveis ao sequestro de radicais livres e à propriedade quelante de metais. Além disso, podem exercer outras atividades biológicas, tais como efeitos nos meios de sinalização celular e na expressão gênica.

A análise de aberrações cromossômicas não apresentou diferenças significativas entre os grupos tratados com 50 e $200 \mathrm{mg} / \mathrm{kg}$ p.c. de EB quando comparadas com o CN, inclusive em comparação da frequência de quebras, gaps e anéis cromossômicos. Em comparação entre o grupo tratado com $100 \mathrm{mg} / \mathrm{kg}$ p.c. de EB com grupo CN, um decréscimo na freqüência de $40 \%$ foi observado (Tabela 2). Esta diminuição pode ser devida à presença de diferentes classes de flavonoides encontradas nos extratos da família Bignoniaceae e no gênero Pyrostegia (Santos \& Blatt, 1998), os quais possuem atividade antimutagênica (Snijman et al., 2007).

De acordo com a análise da freqüência de EPCMN e a porcentagem de células com aberrações cromossômicas em animais tratados com diferentes doses 
de EB de $P$. venusta, foi possível observar um decréscimo em ambos os ensaios. Esta diminuição poderia ser devida à presença de antocianinas florais como descrito por Scogin (1980). Estes resultados estão de acordo com os estudos promovidos por Gasiorowski et al. (1997) e Kong et al. (2003), que descreveram as propriedades farmacológicas destes componentes na proteção contra doenças cardiovasculares atuando como fatores antimutagênicos e antitumorais.

O efeito genotóxico do extrato de $P$. venusta na medula óssea de camundongos foi estudado pela primeira vez no presente trabalho. Os resultados indicam que a mistura de componentes encontrados nestes extratos não causam um aumento significativo no número médio de células com micronúcleos ou aberrações cromossômicas quando administradas em doses de 50 e $200 \mathrm{mg} / \mathrm{kg}$ p.c., assim como diminuem as mesmas nos animais tratados com a concentração de $100 \mathrm{mg} / \mathrm{kg}$ p.c. Embora os resultados do presente estudo não se oponham ao consumo terapêutico do extrato de $P$. venusta, o cuidado quanto ao uso indiscriminado pelo público dessas e outras plantas medicinais, continua sendo necessário.

Finalmente, o estudo proporciona evidências de que os testes in vivo de micronúcleo e de aberrações cromossômicas em roedores são sistemas versáteis e sensíveis para determinação de atividade não genotóxica de $P$. venusta.

\section{AGRADECIMENTOS}

A colaboração de Helber Moreira Machado pela produção dos extratos da planta, Maycon Sthael Alves Gontijo e Geraldo da Silva Xavier Neto pela preparação das lâminas do teste de micronúcleo e aberrações cromossômicas. Este trabalho foi parcialmente financiado por CNPq, FAPEMIG, UNIPAM, UEMG e UNESP.

\section{REFERÊNCIAS}

Al-Majed AA, Al-Yahya AA, Al-Bekairi AM, Al-Shabanah OA, Qureshi S 2006. Studies on the cytological and biochemical effects of valerian in somatic and germ cells of Swiss albino mice. Food Chem Toxicol 44: 18301837.

De Sampaio ES 1991. Padrão de Floração e Aspectos da Biologia de Reprodução de Pyrostegia venusta (KER.) Miers (Bignoniaceae), na Região Metropolitana de Curitibal PR. Curitiba, 120 p. Dissertação de Mestrado, Programa de Pós-graduação em Ciências Biológicas, Universidade Federal do Paraná.

Dubey RC, Misra K 1976. Chemical components of Pyrostegia venusta flowers. $J$ Indian Chem Soc 53: 378-381.

Ferreira TD, Alvares PSM, Houghton PJ, Braz-Fillho R 2000. Constituintes químicos das raízes de Pyrostegia venusta e considerações sobre a sua importância medicinal. Quim Nova 23: 42-46.
Galetto L, Bernardello M, Juliani HR 1994. Characteristics of secretion of nectar in Pyrostegia venusta (Ker-Gawl.) Miers (Bignoniaceae). New Phytol 127: 465-471.

Gasiorowski K, Szyba K, Brokos B, Kolaczynska B, JankowiakWlodarczyk M, Oszmianski J 1997. Antimutagenic activity of anthocyanins isolated from Aronia melanocarpa fruits. Cancer Lett 119: 37-46.

Gilman EF 1999. Pyrostegia venusta. Fact Sheet FPS-496. University of Florida. Cooperative Extension Service. Institution of Food and Agricultural Sciences.

Kong JM, Chia LS, Goh NM, Chia TF, Brouillard R 2003. Analysis and biological activities of anthocyanins. Phytochemistry 64: 923-933.

Krishna G, Hayashi M 2000. In vivo rodent micronucleus assay: protocol, conduct and data interpretation. Mutat Res 455: 155-166.

Ouanes Z, Abid S, Ayed I, Anane R, Mobio T, Creppy EE, Bacha $\mathrm{H}$ 2003. Induction of micronuclei by Zearalenone in Vero monkey kidney cells and in bone marrow cells of mice: protective effect of Vitamin E. Mutat Res 538: 63-70.

Preston RJ, Kean BJ, Galloway S 1987. Mammalian in vivo cytogenetic assays: analysis of chromosome aberrations in bone marrow cells. Mutat Res 189: 157-165.

Raj AS, Katz M 1984. Corn oil and its minor constituents as inhibitors of DMBA-induced chromosomal breaks in vivo. Mutat Res 136: 247-253.

Salamone MF, Heddle JA 1983. The bone marrow micronucleus assay: rationale for a revised protocol. Chem Mutagens 8: 111-149.

Santos MD, Blatt CTT 1998. Teor de flavonóides e fenóis totais em folhas de Pyrostegia venusta Miers. de mata e de cerrado. Rev Bras Bot 21: 135-140.

Satyavathi M, Radhakrishnaiah M, Narayana LL 1984. A note on the phytochemical constituents of some Bignoniaceae. Curr Sci India 53: 711-712.

Schmid W 1975. The micronucleus test. Mutat Res 31: 9-15.

Scogin R 1980. Anthocyanins of the Bignoniaceae. Biochem Syst Ecol 8: 273-276.

Sens SL 2002. Alternativas para a auto-sustentabilidade dos Xokleng da terra indigena Ibirama. Florianópolis, 386 p. Dissertação de Mestrado, Programa Pós-Graduação em Engenharia de Produção, Universidade Federal de Santa Catarina.

Snijman PW, Swanevelderb S, Joubertc E, Green IR, Gelderblom WCA 2007. The antimutagenic activity of the major flavonoids of rooibos (Aspalathus linearis): Some dose-response effects on mutagen activation-flavonoid interactions. Mutat Res 631: 111-123.

Soobrattee MA, Neergheen VS, Luximon-Ramma A, Aruoma OI, Bahorun T 2005. Phenolics as potential antioxidant therapeutic agents: Mechanism and actions. Mutat Res 579: 200-213.

Surh YJ, Ferguson LR 2003. Dietary and medicinal antimutagens and anticarcinogens: Molecular mechanisms and chemopreventive potential-Highlights of a symposium. Mutat Res 523: 1-8. 